\title{
Percent Change from Baseline in Organ Enlargement
}

National Cancer Institute

\section{Source}

National Cancer Institute. Percent Change from Baseline in Organ Enlargement. NCI

Thesaurus. Code C135510.

The current organ enlargement minus the baseline organ enlargement, divided by the baseline organ enlargement, multiplied by 100. 